\title{
O Seminário de Cinema do MASP e a produção documental de Ozualdo Candeias (1955-66)
}

\section{The MASP Film Seminar and the documentary production of Ozualdo Candeias (1955-66)}

\section{Fábio Raddi Uchôa}

Doutor em Ciências da Comunicação pela Escola de Comunicação e Artes da Universidade de São Paulo - ECA/USP. Professor colaborador do Programa de Pós-Graduação em Imagem e Som da Universidade Federal de São Carlos (PPGIS/UFSCar), onde desenvolve pesquisa de pós-doutorado (CAPES-PNPD).

<raddiuchoa@uol.com.br>

\section{RESUMO}

A partir do trabalho com documentação de arquivo, busca-se debater o Seminário de Cinema do MASP enquanto espaço de formação no contexto das indústrias cinematográficas dos anos 1950, esclarecendo a passagem de Ozualdo Candeias pelo mesmo. Após a contextualização de tal experiência educacional, a proposta é a análise da produção documental do cineasta entre os anos 1950-60, pensando-a a partir dos ruídos ante ao modo documental expositivo, bem como pelas presenças de um futuro estilo marcado pela liminaridade. Entre os resultados, verificaram-se três linhas de tensão para a construção da liminaridade: a) as ironias; b) os ruídos propiciados por zooms, movimentos de câmera e enquadramentos não usuais; c) o gosto pelo grotesco e pela experiência visual dos deslocamentos espaciais.

Palavras-chave: Cinema. Documentário. Ozualdo Candeias.

\begin{abstract}
From the work with archive's documentation, we seek to discuss the MASP Film Seminar as a formation space in the context of the film industries of the 1950s, clarifying the Ozualdo Candeias's passage by there. After the contextualization of this educational experience, the proposal is to analyze the documentary production by this filmmaker between the 1950-60s, thinking it from the disruptions against the expositive documentary mode, as well from the presences of a future Candeias's style featured by the liminality. Among the results, we verified three tension's lines for the liminality's construction: a) the ironies; b) the noises propitiated by zooms, camera movements and unusual frameworks; c) the preference for the grotesque and for the visual experience of spatial displacements.
\end{abstract}

Keywords: Film. Documentary. Ozualdo Candeias.

\section{Apresentação}

Os estudos realizados sobre Ozualdo Candeias concentram-se no período maduro de seu trabalho (1967-1992), com um conjunto de filmes conhecidos pela não classificação e pelos traços limítrofes, já estudados e interpretados por alguns pesquisadores (Ramos, 1989; Gamo, 2000; Bernardet, 2002; Machado Jr, 2007; Uchoa, 2013). Apesar deste considerável avanço, quase nada foi dito acerca do período de aprendizado. Vale lembrar que, em 1967, quando do

1 Pesquisa apoiada por Arquivos Pessoais da Cinemateca Brasileira e Arquivo Histórico do MASP. 
lançamento de seu primeiro longa, o cineasta tinha mais de 40 anos de idade e, no mínimo, 12 anos de experiência profissional como documentarista. Desde o início de sua prática cinematográfica, durante os anos 1950, Candeias realizou documentários institucionais, atualidades e filmes publicitários, acompanhando um período particular do mercado cinematográfico paulista. Sua trajetória pessoal mescla-se a um momento de transição, entre a decadência dos estúdios paulistas (Vera Cruz, Maristela e Multifilmes) e a consolidação da Boca do Lixo como polo de produção cinematográfica; entre o projeto de intervenção na cultura pela burguesia paulista, com a tentativa de incorporação de um modelo de produção americano e referenciais europeus (Galvão, 1981), e a consolidação de um cinema de produção rápida, com baixos custos e inspiração no universo erótico (Abreu, 2006; Simões, 1981). O intuito do presente artigo é ampliar o debate sobre o Seminário de Cinema do Museu de Arte de São Paulo (MASP), tomado como passo inicial para contextualizar e debater a obra documental de Ozualdo Candeias, realizada neste período de lusco-fusco. Para tanto, enfatizaremos o referido seminário, na qualidade de uma experiência que reúne profissionais provenientes das empresas cinematográficas paulistas dos anos 1950 e formação de futuros profissionais do cinema paulista. Espaço onde Candeias aprimora conhecimentos e realiza importantes contatos de trabalho, inserindo-se na produção de atualidades e filmes institucionais. Num segundo momento, averiguaremos a formação da prática cinematográfica de Candeias, comum conjunto de documentários realizados entre 1955 e 1966 - Tambaú, cidade dos milagres (1955), Marcha para o Oeste n. 3 (195-), Marcha para o Oeste n.5 (195-), Rodovias (1962), Ensino industrial (1962) e Casa André Luiz (1966). Os mesmos serão examinados, em busca de resíduos liminares, ou seja, momentos onde os traços estilísticos coletivos, especialmente associados ao documentário expositivo², sofrem interferências autorais.

Com isso, espera-se trazer informações sobre uma experiência educacional pouco estudada, o Seminário de Cinema do MASP, a partir de pesquisas realizadas junto do Arquivo Histórico do MASP e ao Arquivo Pessoal de Plínio Garcia Sanchez (Cinemateca Brasileira). Em sintonia com este contexto, com o debate da produção documental de Ozualdo Candeias dos anos 195060 , procura-se demonstrar que o cineasta encontra na prática cinematográfica do período um engenhoso campo de experimentação para a futura afirmação de um estilo pessoal.

2 O assim chamado modo expositivo é, para Bill Nichols uma forma de documentário que se dirige diretamente ao espectador por meio de vozes ou legendas, propondo uma determinada perspectiva de mundo. Uma de suas marcas é a voz over ou voz de Deus (Nichols, 2012, p.142). 


\section{O cinema paulista dos anos 1950 e o Seminário de Cinema do MASP como espaço de formação de técnicos}

Para o mercado cinematográfico paulista, a década de 1950 pode ser pensada como uma espécie de era dos extremos. Durante a primeira metade, há uma grande euforia industrial. A partir da debacle da Vera Cruz (1954), notase a intensificação da crise e o acalorar dos debates em torno da legislação do cinema brasileiro, no âmbito dos Congressos de Cinema (1952-53) e das Comissões de Cinema (Municipal e Estadual de São Paulo em 1955; Federal em 1956). Como sugere José Mario Ortiz Ramos, a falência da experiência industrial paulista dos anos 50 leva a uma mudança de paradigma, com o debate da presença do Estado no mercado cinematográfico por diferentes grupos, que gravitariam em torno dos futuros polos nacionalista e universalista em termos de pensamento cinematográfico (Ramos, 1983) ${ }^{3}$.

A passagem entre as décadas de 1940-50 é um período de efervescência cultural, com a consolidação de museus, escolas de arte, bem como de companhias de teatro e cinema. Entre tais instituições estão o MASP (1947), o Teatro Brasileiro de Comédia (TBC) (1948), o Museu de Arte Moderna de São Paulo (MAM-SP) (1949), a Companhia Cinematográfica Vera Cruz (1949) e, posteriormente, a Maristela (1950) e a Multifilmes (1952). Em tal período, a importação de cultura e de técnicas artísticas soma-se à formação efetiva de quadros profissionais. No caso do cinema, isso se dá pelo trabalho efetivo nas empresas, bem como pela experiência de ensino, como aquela iniciada pelo MASP em 1949, onde parte dos técnicos estrangeiros trazidos pelas produtoras lecionará.

Pouco tempo após sua fundação, o MASP investe na realização de atividades cinematográficas, dando-lhes um reconhecimento equivalente àquele de outras práticas artísticas, como as artes plásticas, a arquitetura e o teatro. Assim, vinculado às atividades do Centro de Estudos Cinematográficos ${ }^{4}$ do MASP, seria inaugurado o Seminário de Cinema, um dos primeiros cursos do

3 Como descrito por Ortiz Ramos (1983), a partir do final dos anos 1950, assumem contornos mais nítidos o embate entre dois grupos de cineastas e críticos. Estes se articulavam diante da discussão da atuação do Estado no campo cinematográfico. A corrente "industrialista-universalista" opunha-se à ala nacionalista e defendia a absorção das formas de produção estrangeira, sem prejudicar os fornecedores externos. Tal grupo era formado por ideólogos das extintas Vera cruz, Maristela e Multifilmes. Já o grupo nacionalista, relacionado à defesa do nacional e do popular, seria composto por membros do cinema independente, do Cinema Novo e ex-integrantes da Revista Fundamentos, tais como Alex Viany e Nelson Pereira dos Santos.

4 Entidade de natureza cultural e artística tendo por objetivo a divulgação do cinema como forma de arte. Constituída em 1949. Presidente: Paolo Giolli. Vice-Presidente: Carlos Ortiz. Sede na Rua Sete de Abril, n. 216, São Paulo. 
gênero organizado no país. O mesmo teve uma primeira edição em 1949, com duração de quatro meses ${ }^{5}$ e aulas predominantemente teóricas (Sternheim, 2009, p. 38), cujos moldes foram transformados a partir de janeiro de 1951.

Em Outubro de 1949, no contexto do primeiro Seminário de Cinema, a presença de Alberto Cavalcanti para uma série de conferências ${ }^{6}$ reafirmaria as ambições do Centro de Estudos Cinematográficos em promover atividades de cunho cinematográfico. O interesse pelo cinema dialogava com a concepção artística do MASP que, fundado em outubro de 1947 por Pietro Maria Bardi e Assis Chateaubriand, opunha-se às noções estanques de museu, concebendo-o como espaço de convívio, educação, pluralidade artística e de formação de público. Tal tendência era contemplada por um sistema "anti-museu" (Bardi, 1979 , p. 9) de apresentação das obras em rodízio, com base em pesquisas feitas com os próprios frequentadores.

Em seu primeiro volume, a revista Habitat publica um artigo de Pietro Maria Bardi, colocando o museu como instituição voltada ao público não preparado e à ação didática, incluindo dois auditórios para exibição de filmes, bem como uma série de cursos especiais, abrangendo Desenho com modelo natural, História da Música, Gravura, Fotografia, entre outros (Bardi, 1950, p. 17). Em sintonia com estas ambições, o curso de Cavalcanti associava o MASP ao ensino do cinema, com todos os alardes imagináveis via imprensa, compondose a partir de um olhar eminentemente técnico, para a formação de profissionais do cinema. Para coroar o grande evento, o Centro de Estudos Cinematográficos contataria o Consulado Inglês, para colaborar com os tramites necessários à vinda dos documentários Film and reality (1939-42), Night Mail (1936) e North Sea (1937), realizados com a participção de Cavalcanti na Inglaterra7.

O projeto de um centro de formação se consolidaria em janeiro de 1951, com a reelaboração do Seminário de Cinema, agora em novo formato e com ambições de se transformar em instituição perene de ensino. Inicialmente,

5 As aulas distribuíam-se entre as seguintes matérias: História do Cinema (Carlos Ortiz); Técnica de Cinema, Argumento, Decupagem e Montagem (Tito Batini); Ótica (Abraão Schultz); Câmera de Filmagem (João Korani); Fotografia no cinema (Antonio da Silva Vítor); Interpretação, cenografia, maquiagem e filmagem (Oswaldo Sampaio); Tecnicolor e som (Nazim Athié). (Cf. BARBOSA E SILVA, Florentino. "Um Seminário". Habitat, São Paulo, n.2, jan.-mar. 1951, p. 82-83.)

6 As conferências de Cavalcanti abordaram os seguintes temas: "Introdução; possibiliade do cinema na Indústria Brasileira/ Produção / Argumentos, Assuntos e Cenários/ Direção/ O lado visual do filme/ O som e a música/Interpretação/ Parte técnica e equipe técnica/ Montagem e ritmo/ Conclusão, filme em geral e juízos estéticos." (SEMINÁRIO DE CINEMA. Conferências de Alberto Cavacanti. Arquivo Histórico do MASP, Série "1949 - Curso de Cinematografia". Caixa 3 Pasta 14.)

7 BARDI, P.M. [Carta para o Consulado Inglês]. São Paulo, 28 set. 1949. Arquivo Histórico do MASP, Série"1949 - Curso de Cinematografia". Caixa 3 Pasta 14. 
tratava-se de um curso de dois semestres, realizado durante o período noturno. Depois, a duração seria aumentada para três semestres, sendo a proposta de dois primeiros dedicados às aulas teóricas e semipráticas, e o terceiro às aulas práticas, compreendendo a realização de filmes. Seu orçamento inicial, somente para a instalação e manutenção do primeiro ano de funcionamento do curso, tinha ares empreendedores. Além da contratação de professores e técnicos do mercado paulista, muitos deles atuantes nas produtoras paulistas dos anos 1950 (Vera Cruz, Maristela e Multifilmes), constam no projeto os gastos para a manutenção de biblioteca, publicações técnicas, exibição de filmes para estudo e, sobretudo, de um forte departamento de Produção.

Assim, o projeto incluía equipamentos de filmagem, projeção, gravação, iluminação, entre outros materiais necessários para a realização de filmes pelos alunos, num curso cuja ambição, em termos de proposta, era a prática e o conhecimento das técnicas ${ }^{8}$. De fato, alguns documentários educativos seriam realizados pelos alunos em cooperação com os professores. O filme Os Tiranos $(1951)^{9}$, por exemplo, apresenta um criativo trabalho em table-top a partir de imagens de um quadro de Antoine Caron, pertencente ao acervo do MASP. ${ }^{10}$ Vale lembrar que essa proposta didática, incluindo apresentação de obras de arte e o trabalho com table-top, teria reflexos posteriores obra de Ozualdo Candeias, seja em filmes como Zézero (1974), onde o table-top é incorporado com criatividade narrativa, seja nos documentários História da Arte no Brasil (1979), realizados em vídeo para a TV Cultura.

Entre os professores do Seminário de Cinema, que seria posteriormente transferido para a Fundação Armando Alvares Penteado, há uma significativa presença de figuras do cinema industrial e do pensamento cinematográfico universalista paulista, com algumas exceções. O núcleo de docentes seria composto por nomes como: Plínio Garcia Sanchez, Maximo Barro, John Waterhouse, Jacques Dehenzelin, Juan Carlos Landini, Rodolfo Nanni, Flávio

8 O orçamento para instalação e manutenção do primeiro ano totaliza o investimento de Cr\$ 6.288.800,00. (SEMINÁRIO DE CINEMA. Anteprojeto de Orçamento. Arquivo Histórico do MASP - Série "Evento de cinema - Seminário". Caixa 3 Pasta 6.)

9 Direção de Produção (Plínio Garcia Sanchez); Direção e Roteiro (Marcos Margulies); Continuidade (Zulmira Ribeiro Tavares); Assistente de Montagem (Luiz Carlos Bresser Pereira). Fonte: Filmografia Brasileira. Disponível em: <http://www.cinemateca.gov.br>. Acesso em: 15 abr. 2015. Artigo do período indica que o filme teria sido exibido como complemento de Alameda da Saudade, 113, de Carlos Ortiz, em 1951. ) (Cf. A. “Lançado em circulação o primeiro filme produzido pelo Museu de Arte de S. Paulo. Diário de S. Paulo, São Paulo, 30 dez. 1951.)

10 "Os alunos dividiram a tela em vários episódios, sublinhando a importância dos acontecimentos e tirando de cada detalhe o máximo de significado". (MARGULIES, Marcos. Documentários. Habitat, São Paulo, n. 5, 1951, p. 34.). 
Motta, Luiz Giovanini, Thomas Farkas, José Cañizares ${ }^{11}$, Neli Dutra, Antonio Augusto Cavalheiro Lima e Sérgio Alvarez ${ }^{12}$, incluindo referências a participações de Claudio Santoro, Ricardo Sievers, Walter Hugo Khouri, Flávio Tambellini, Alfredo Palácios, B.J. Duarte, Rui Santos e Werner Staehelin ${ }^{13}$. Alguns de tais nomes foram alunos do Seminário antes de se tornarem professores.

Passaram pela coordenação do Seminário Plinio Sanchez e Marcos Margulies, entre outros. Quanto ao ensino, era herdeiro da euforia industrializante. Inicialmente foram criadas disciplinas teóricas como História do Cinema, Gramática do Cinema e Estética e História da Arte, tendo entre os professores principalmente críticos e teóricos do cinema. Algum tempo depois, porém, imaginou-se um plano de ensino sólido, cujas disciplinas dividiam-se entre as principais tarefas técnicas, do cinema pensado como produção industrial ${ }^{14}$. Com o tempo, técnicos da Vera Cruz e da Maristela foram incorporados ao quadro docente, tornando praxe o convite a alunos do museu para integrar momentaneamente equipes de filmagem ou a trabalhar diretamente nos laboratórios e estúdios.

A ambição presente nas propostas e planos de ensino era de propiciar um contato direto com as técnicas. Assim, não apenas se exigia a redação de argumentos e roteiros, mas também se previa a prática direta de laboratório, exercícios de fotografia e iluminação, exercícios práticos de montagem, construção de cenários etc. A partir da turma do segundo semestre de 1952, ambicionava-se uma intensificação das "aulas práticas, com visitas a laboratórios e estúdios cinematográficos, assistindo in loco os processos de revelação, copia, corte, montagem, sonorização, dublagem etc." (MUSEU..., 30 ago. 1952).

11 Editor da Maristela.

12 Engenheiro de Som da Maristela.

13 Chefe de laboratório da Cinematográfica Bandeirante.

14 As disciplinas, referidas nos planos de ensino dividem-se em: Produção; Argumento; Roteiro; Direção; Assistência de direção; Fotografia e iluminação; Edição e Montagem; Laboratório; Som e projeção; Cenografia; Desenho e costumes; Fotografia e lluminação; História do cinema. (SEMINÁRIO DE CINEMA. Planos de Ensino. Arquivo Histórico do MASP - Série "Evento de cinema - Seminário". Pasta 6, Caixa 3.) [A data provável é de 1955.] Ao longo de 1955, o Seminário adquiriria um formato mais complexo, dividindo-se em três ciclos letivos, de seis meses cada um. 10 Ciclo - História do Cinema; Estética e História da Arte; Argumento e elementos de adaptação; Roteiro e enquadramento; Anotação e continuidade; Produção, elementos de organização: o diretor de Produção. $2^{\circ}$ Ciclo - Iluminação e elementos da composição; câmera e elementos de ótica; Som, projeção e elementos de eletrônica; Edição: corte e montagem; Laboratório, trucagem e elementos de química; Direção e elementos de interpretação; Cenografia; $3^{\circ}$ Ciclo - Legislação cinematográfica; Crítica cinematográfica; Publicidade em cinema; Maquiagem e caracterização; Costumes; Dicção e elementos de dublagem; Música no filme e elementos de música. "Relatório Seminário de Cinema - agosto de 1955". Arquivo Plínio Garcia Sanchez - Centro de Documentação e pesquisa da Cinemateca Brasileira. 
A abrangência das atividades realizadas pelo Departamento de Cinema do museu são visíveis nos Boletins do MASP, do ano de 1954, onde suas diversas frentes são apresentadas ao público: conferências semanais, debates com técnicos e cineastas de filmes em cartaz, projeção de longas-metragens duas vezes por semana, programa de cinema destinado ao público infantil, edição de publicações sobre cinema brasileiro e mundial que seriam distribuídas gratuitamente aos sócios, espaço em coluna do Diário de São Paulo para divulgação de escritos críticos e atividades cinematográficas do museu, bem como o estabelecimento de intercâmbios internacionais, com países como França e Uruguai. O direcionamento prático, porém, por muito esbarrou na limitação de recursos financeiros. Os exercícios técnicos se davam em contato com laboratórios e estúdios do período.

A efetiva compra de equipamentos, por sua vez, seria alcançada somente a partir de dezembro de 1957, com o estabelecimento de um Convênio Cultural com a Prefeitura de São Paulo. ${ }^{15}$ Em termos institucionais, porém, 1958 será um ano conturbado para o Seminário. Trata-se de um período de transferência dos cursos do MASP para a FAAP, no qual o Seminário vê-se obrigado a manter o vínculo em termos de sede com o MASP, para não causar possíveis constrangimentos ao referido Convênio Cultural com a prefeitura. ${ }^{16}$ Tendo em vista as possibilidades de aporte institucional permitidos pela FAAP, algum tempo depois o Seminário foi definitivamente transferido, levando a novas reformulações que originariam o atual curso de cinema daquela instituição.

A inscrição no Seminário de Cinema era precedida por uma prova de conhecimentos básicos de arte, cinema e indagações sobre os gostos artísticos do candidato, além de um exame médico para comprovação de sanidade mental. Durante os primeiros anos de funcionamento, o curso teve grande procura, formando alguns alunos que se tornariam figuras de relevância para o cinema e para a crítica paulista. Entre eles: Roberto Santos, Galileu Garcia, Olavo Costa, Glauco Mirko Laurelli, Juarez Dagoberto, Plinio Garcia Sanchez, Sergio Tofani, Luis Sérgio Person, Nelson Xavier e Antunes Filho (Guimarães, 2008). A

15 Um convênio Cultural, estabelecido com a Prefeitura de São Paulo, rendeu ao Seminário de Cinema 3.000.000 de cruzeiros, dos quais 2.000.000 foram investidos na compra de equipamentos e 1.000.000, controversamente concedido de empréstimo à FAAP - Fundação Armando Alvares Penteado. Entre os equipamentos que foram adquiridos: moviola vertical; câmeras 35mm; tripé para câmera Dobrie; grua comercial para filmagem; refletores; tripés para refletores; 1 viatura Volkswagen; lâmpadas para iluminação. ("Seminário de Cinema: Histórico" Arquivo Plinio Garcia Sanchez - Centro de Documentação e pesquisa da Cinemateca Brasileira.)

16 De acordo com o contrato, no caso de dissolução do Seminário, os equipamentos adquiridos deveriam ser devolvidos à Prefeitura. 
relação de formados/inscritos em outubro de 1952 aponta também: Zulmira Ribeiro Tavares, Eliseo Fernandes, Carlos Maximiano Motta e Ely Azeredo. Outras figuras importantes, como Eduardo Coutinho, também passariam pelo curso ao longo da década, embora a crise das grandes empresas tenha provável reflexo sobre a procura pelo curso do MASP.

Como possível decorrência deste declínio, dos alunos matriculados entre os anos 1955-57 poucos estavam diretamente relacionados ao trabalho com cinema, havendo algumas exceções como o caso de Ozualdo Candeias, que usa o próprio curso para articular relações de trabalho no campo do cinema. A partir de 1958, há uma renovação da procura pelo curso, provavelmente devido à transferência para a FAAP, aos investimentos em equipamentos e à decorrente transformação do curso. Entre os alunos de 1959, constam J-C. Bernardet, Sérgio Augusto e Pedro Carlos Rovai.

Os materiais analisados do Seminário de Cinema, uma documentação sobretudo administrativa, sobressai uma visão do cinema como indústria, embora sem matizes ideológicos totalmente definidos. Como se pode averiguar a partir das pesquisas de Maria Rita Galvão e Bernardet (1983), por Ortiz Ramos (1983) e por Arthur Autran (2013), diversas são nuances do pensamento industrial, em torno de noções como a industrialização, o cosmopolitismo, o universal, o nacional, a cultura popular e a representação da realidade brasileira. Entre os professores e dirigentes do Seminário de Cinema, há uma maioria de realizadores identificados com um cinema dito universal, como Walter Hugo Khouri e Flávio Tambellini, mas também pensadores como Carlos Ortiz, em sintonia com da revista Fundamentos e um nacionalismo de esquerda atuante (Catani, 2007, p. 296), cujas influências em termos de pensamento devem ser melhor exploradas.

Em termos de gerenciamento e de proposta formal de ensino, por sua vez, nota-se uma visão do cinema como produto, realizado a partir de um trabalho industrial, dividido em etapas e funções particulares, possivelmente em sintonia com o cinema clássico e o sistema de produção hollywoodiano. Vale destacar que não há um posicionamento, uníssono e identificável, ante à cultura e à incorporação da realidade brasileira em termos cinematográficos. A experimentação presente em um dos filmes realizados pelos alunos, Os Tiranos (1951), por outro lado, permite pensar num curso que unia ambições industriais e certa abertura para experimentações de linguagem.Nicho este que aparentemente será explorado por Candeias em suas primeiras experiências no campo do cinema documental. 


\section{Os primórdios da prática cinematográfica de Ozualdo Candeias}

Apesar de realizar seu primeiro longa-metragem em 1967, a partir de um estilo aparentemente autodidata, Candeias possui uma trajetória anterior, com documentários institucionais e atualidades. Filho de família de agricultores e imigrantes, Candeias passou a infância transitando por diversas cidades do país, entre São Paulo, Rio de Janeiro, Mato Grosso e Recife. Depois de fazer um pouco de tudo, como vendedor de sorvete, office boy, e de servir ao exército durante o período da segunda guerra, Candeias fixou-se em São Paulo, a partir do final da década de 1940, trabalhando como caminhoneiro e fiscal da prefeitura - a admissão como funcionário municipal coincide com o ano de fundação do MASP (1947). Seus primeiros contatos com o cinema teriam se dado por curiosidade, em busca de filmar discos voadores com uma Keystone durante as viagens de caminhão, entre São Paulo, Paraná e Mato Grosso.

O tino para a mecânica, desenvolvido desde a infância quando colaborava com a produção de queijo mantida pelo pai em Mato Grosso, Ihe estimula o interesse pelo cinema e a facilidade no trato com o maquinário cinematográfico. $\mathrm{O}$ aprendizado se dá inicialmente a partir de livros técnicos. Por intermédio do fotógrafo da Maristela Eliseo Fernandes, Candeias consegue os primeiros trabalhos no campo do cinema, que seriam realizados em contato com a Maristela, e também com a Vera Cruz. Em 1955, ainda sem conhecimentos consolidados sobre a sétima arte, realizaria o documentário em curta-metragem, Tambaú, a cidade dos milagres, produzido por R. P. Dimbério da Boca do Lixo.

É neste período, de importação de uma forma de produção cinematográfica e de técnicos da área para São Paulo, que Candeias inicia sua formação cinematográfica. Eliseo Fernandes o estimula a participar do Seminário de Cinema do MASP, que seria cursado pelo cineasta entre os anos 1955-5717. Em seu exame de admissão, provavelmente realizado na presença de Plínio Garcia Sanchez, coordenador do curso naquele momento, percebe-se um considerável conhecimento cultural, acompanhado por tacanho e irônico antieruditismo. Ao ser questionado sobre os nomes de cineastas como Alberto Cavalcanti, René Clair, Lumière e Tom Payne, a resposta foi positiva, mas quando estimulado a listar os principais filmes de sua preferência e indicar o motivo, a lista inicia-se por “Documentário sobre animais de W. Disney (Real) / Históricos -

17 O prontuário do aluno, junto ao Arquivo Histórico do MASP, indica 30 jun. 1955 como data de início e mar. 1957 como data final de realização das provas por Candeias. Apesar disso, o cineasta apresenta em seus currículos o período 1956-59 para a mesma atividade. (Cf. CANDEIAS, Ozualdo. [Currículo do cineasta] (1980) Arquivo Plínio Garcia Sanchez - Centro de Documentação e Pesquisa da Cinemateca Brasileira.) 
Egípcio (Por retratar essa época)", para somente depois referir-se a filmes como Ladrões de Bicicleta (1948), O cangaceiro (1953), Salário do medo (1953) e Janela indiscreta (1954).

Alguns dos professores e alunos do Seminário de Cinema fizeram parte do círculo inicial de contatos, trabalhos e indicações de Candeias. Tais contatos incluíam, principalmente, técnicos da Vera Cruz, da Maristela, da Divulgação Cinematográfica Bandeirante, entre outras produtoras que investiam na realização de educativos, institucionais e complementos nacionais para o mercado exibidor. A partir destas e outras referências, o cineasta começa a realizar reportagens para cinejornais, como o Bandeirantes na Tela, o Notícias Catarinenses, o Jogos Nordestinos, entre outros. Foi também estimulado pelas relações estabelecidas no Seminário do MASP, com Plínio Sanchez, Máximo Barro, Flávio Tambellini e posteriormente com Jacques Deheinzelin, que Candeias viabilizou a realização dos documentários Polícia Feminina (1960), Ensino Industrial (1962) e Rodovias (1962), considerados por ele como filmes de aprendizado (Autran; Heffner e Gardnier, 2002, p. 19).

Em tal contexto dos anos 1950-60, a produção de Candeias é heterogênea, contendo porém pontos de contato com o terreno mais amplo das atualidades e dos documentários institucionais. Trata-se de materiais que unem os elogios às autoridades e ao Estado, sob o viés daquilo que Paulo Emílio Salles Gomes denominou de "ritual do poder" (Gomes, 1986, p. 325), com a representação de efemérides e figuras públicas. Percebe-se também o assim chamado "modo expositivo", com ênfase à impressão de objetividade e à voz over acima que qualquer questionamento, onde o "tom oficial do narrador oficial, como o estilo peremptório dos âncoras e repórteres de noticiários empenha-se na construção de uma sensação de credibilidade, usando características como distância, neutralidade, indiferença e onisciência." (Nichols, 2012, p. 144.). Atualidades ou filmes institucionais, ambos inserem-se num mercado com regras de circulação e formas narrativas particulares que possuem suas regularidades e reconhecimentos coletivos. No caso das atualidades, a marca é a produção rápida e serial. Já nos documentários institucionais, trata-se da propaganda de empresas ou do próprio Estado, elaboradas em alguns casos com maior espaço para manobras criativas, como a opção por excertos encenados onde, engenhosamente, a fala dos personagens pode assumir a função da voz over. Nas realizações de Candeias dos anos 1950-60, tais traços se misturam. Isso inclui as atualidades ambientadas em pequenas cidades do Mato Grosso (Interlândia ou Marcha para o Oeste), os filmes institucionais realizados para a Prefeitura ou para o Estado de São Paulo (como Polícia Feminina, Ensino Industrial e 
Rodovias), os institucionais para entidades beneficentes (Casa André Luiz), bem como o documentário de romaria Tambaú, cidade dos milagres. Em todos estes casos, trata-se de um tipo de material que se insere no mercado na qualidade de complemento nacional. Ou seja, realizado com rapidez, transmitindo um discurso oficial e, em termos narrativos, marcados pela voz over, pelas trilhas sonoras oficialescas, além de uma montagem e de enquadramentos que tendem a reafirmar as formulações feitas pelo narrador (voz over).

Gradativamente, ao longo dos anos 1960, Candeias se fixará em torno das relações sociais estabelecidas junto à Boca do Lixo, seja para colocar-se como mão de obra técnica para a realização de comédias eróticas, seja para um trabalho pessoal afinado com o dito Cinema Marginal, do qual será considerado um dos antecessores. A partir de 1967, com o longa A margem, inicia-se um processo de afirmação autoral e "depuração do estilo" (Bernardet, 2002) dos filmes de Candeias. Os mesmos se caracterizarão pelo enfoque às populações excluídas, por certa ironia, pela mescla entre culto e popular, bem como por traços de perambulação (Douchet, 1999) presentes em diversas instâncias. As singularidades da produção de ficção em média e longa-metragem, concentrada entre os anos 1967-92, foram interpretadas de diversas maneiras por pesquisadores. Alguns centram-se na perambulação e na ambivalência enquanto traços narrativos marcantes. Em Cinema Marginal (1968-73), (Ramos, 1987, p. 86-89) o cinema de Candeias é pensado a partir da coexistência entre o sublime e o abjeto, que se desdobra numa busca pela pureza mesmo em meio ao lixo. A partir de Aves sem rumo (Gamo, 2000), pensa-se na noção de transitoriedade e seus reflexos em diferentes instâncias nos filmes do cineasta, incluindo as práticas de roteiro, produção e de estilo. Em "Uma São Paulo de revestrés" (Machado Jr., 2007), os filmes do cineasta são explorados a partir de suas ambiguidades, sob o viés de um estilo compósito entre banalidade e sonho, com personagens que gravitam como asteroides em torno dos adensamentos urbanos. Outra porta de entrada é pensar na ambiguidade e na subversão, no trato com formas narrativas hegemônicas, como traço de funcionamento próprio à obra do cineasta. Assim, as relações estabelecidas com algumas referências narrativas, como o western, as comédias eróticas, ou o documentário em seu modo expositivo, apresentam-se como flancos profícuos. ${ }^{18}$ Trata-se de um estilo individual que, ante a narrativas hegemônicas ou em pauta em determinados

18 Entre os trabalhos recentes, a tese Perambulação, silêncio e erotismo nos filmes de Ozualdo Candeias (UCHOA, 2013) colabora para definir a obra de Candeias a partir das relações de subversão e ambiguidade ante ao cinema de perambulação, ao western e às comédias eróticas. 
contextos, afirma-se por uma transposição jamais destituída de ironia. Tal traço apresenta-se desde os primeiros trabalhos do cineasta.

\section{Estilo e liminaridade: aportes teóricos}

O debate dos filmes de Cadeias apresentado no próximo tópico parte de uma premissa particular: nos documentários do cineasta, pode-se identificar momentos fugazes, onde o predomínio de um modelo serial coletivo é rompido por presenças autorais, explicitando os traços liminares de um estilo individual em gestação. Assim, em termos metodológicos, dialogaremos com duas ideias que merecem esclarecimento: estilo e liminaridade.

Nos campos da história da arte, da estética e da estilística, a definição de estilo remonta ao início do século XX, com autores como Schapiro (1982), Wolfflin (2000) e Panofsky (1995), que propõem apreensões gerais e de fôlego para o termo. Neste contexto, pode-se destacar a formulação de Meyer Schapiro, para quem "Por estilo compreendemos a forma constante - e por vezes os elementos, as qualidades e as expressões constantes - na arte de um indivíduo ou de um grupo de indivíduos." (1982, p. 25).

Nos estudos de cinema, partindo da concepção colocada por Bordwell e Thompson (1997, p. 357), o estilo é um sistema formal que diz respeito às técnicas empregadas por um cineasta e ao modo como as utiliza; nele influenciam as escolhas pessoais dos cineastas, bem como as conjunturas histórico-cinematográficas e de produção. Trata-se da "aparência dos filmes" ou, de maneira mais aprofundada, de "um uso sistemático e significativo de técnicas da mídia cinema em um filme" (Bordwell, 2013, p. 17). Tal definição pode ser usada para pensar em práticas estilísticas coletivas, sendo a configuração particular dos diferentes domínios envolvidos numa produção em série, como a mise-en-scène, o enquadramento, o foco, o figurino, a direção de atores, a disposição dos interpretes no quadro, bem como o uso do som.

No contexto do cinema moderno, a questão do estilo avança junto a um debate autoral, associado à denominada política dos autores. Entre a crítica francesa dos anos 1950-60, a idéia de mise en scène foi amplamente utilizada, para questionar a presença dos traços de um autor/cineasta num filme, podendo ser pensada como um equivalente à idéia de estilo. $O$ termo usado pelos críticos dos Cahiers du Cinema permite pensar em estilos individuais, próprios a determinados cineastas e somente a eles, colaborando para explorar traços ao mesmo tempo formais e subjetivos. De acordo com Jean-Claude Bernardet $(1994$, p. 31), a tal tipo de abordagem interessa o autor como um cineasta que se repete, permitindo a identificação de um sistema de redundâncias: as repetições 
e similitudes que permitem delinear uma "matriz" (Bernardet, 1994, p. 31), virtualidade que será repetida de maneira obcecada ao longo da filmografia de um diretor.

Os filmes de Candeias que serão aqui abordados constituem um momento de maturação e transformação na obra do cineasta, onde o estilo coletivo das atualidades e documentários institucionais sofre a interferência de fragmentos autorais, que marcarão a futura matriz do estilo maduro. Terminologicamente, tratamos de momentos de não-classificação, que podem ser experimentalmente aproximados da noção de liminaridade. Proveniente da Antropologia da performance teatral, o conceito é usado por Van Gennep e Victor Turner, para se referir aos indivíduos de passagem entre uma posição de status para outra. Segundo Van Gennep, trata-se de classificar qualquer pessoa que flutua entre dois mundos (Van Gennep, 1978, p. 36). Já para Victor Turner, "Os atributos de liminaridade, [...] são necessariamente ambíguos [...] esta condição e estas pessoas furtam-se ou escapam à rede e classificações que normalmente determinam a localização de estados e posições num espaço cultural." (Turner, 1974, p. 116-117). Enquanto na Antropologia o termo é usado para rituais de passagem, como a puberdade ou a morte, no cinema o aplicaremos para pensar nos primórdios da apuração de um estilo, onde certas práticas narrativas não têm poder para serem socialmente reconhecidas pelos espectadores enquanto um sistema de coerência individual.

Nos filmes de Candeias dos anos 1950-60, as liminaridades são momentos de dissonância estilística, onde o documentário em sua modalidade clássica sofre interferências autorais. Apropriando-nos de formulações de Bill Nichols, de Introdução ao Documentário, trata-se de contextos onde o modo expositivo é transpassado por fragmentos performáticos; onde a tendência à objetividade é visitada por uma "virtualidade" (Bernardet, 1994, p. 53) em gestação, que futuramente se desdobrará na depuração de um estilo próprio. Não há elementos consolidados, mas sim tentativas fragmentares, de um cineasta que parece passar por um rito de formação e passagem, escapando momentaneamente às classificações narrativas.

\section{Mapeamento da produção documental dos anos 1950-60}

Para pensar em traços liminares nos documentários realizados por Ozualdo Candeias entre os anos 1955-67, período que precede o lançamento do primeiro longa (A margem, 1967), foram selecionados para análise seis curtas- 
metragens realizados no período: Tambaú, cidade dos milagres (1955) ${ }^{19}$, Marcha para o Oesten. 3 (195-) ${ }^{20}$, Marcha para o Oeste n.5 (195-), Rodovias (1962) ${ }^{21}$, Ensino industrial (1962) 22 e Casa André Luiz (1966) ${ }^{23}$. Apesar da grande heterogeneidade, cada um a seu modo apresenta momentos de descompasso estilístico, criando ruídos no contexto de origem e antecedendo fragmentos do futuro estilo autoral maduro. Nesta produção documental do cineasta, as liminaridades diferenciam-se quanto à sua manifestação, dividindo-se entre três linhas de tensão principais: a) a criação de ironias, a partir dos descompassos entre as imagens e a narração em voz over; b) os ruídos narrativos propiciados por zooms, movimentos de câmera e enquadramentos não usuais; c) o gosto pelo grotesco e pela experiência visual dos deslocamentos espaciais, por vezes aproximandose de uma visão de mundo dos personagens.

Tambaú, cidade dos milagres (1955), é um documentário de estrutura predominantemente convencional, que apresenta a peregrinação de romeiros à cidade de Tambaú (SP), para receber as bênçãos do Padre Donizetti. O filme acompanha o trajeto e a situação geral dos devotos: a viagem de trem em direção à cidade de destino cujas ruas estão tomadas por visitantes, a forma como os romeiros esperam, amontoados, muitos deles doentes, deficientes e esfomeados, e por fim, a aparição do Padre Donizetti e a missa por ele rezada. A liminaridade apresenta-se, aqui, por meio do descompasso, entre as imagens de pobreza dos romeiros amontoados e a ordem civil e religiosa imposta pelo conteúdo sonoro (voz over e músicas com temas sacros). Em termos de construção imagética, com sua atenção à pobreza e à degradação humana a partir de planos documentais, notamos certo diálogo com a estética neorealista, porém carregado no gosto pelo disforme e pelo grotesco.

A voz over cumpre em Tambaú, cidade dos milagres uma função parecida com aquela da narração em filmes de atualidade: a contextualização, com tom oficial e por vezes grandiloquente, das ações vistas nas imagens. Por outro lado, há espaço para alguma ironia, por exemplo quando o narrador refere-se à aglomeração de romeiros na praça, a partir da ideia de um movimentadíssimo "mercado" de artigos religiosos; ideia que indiretamente ecoará, mais adiante,

19 Ozualdo Candeias (Direção, roteiro, fotografia e montagem); R.P. Dimbério (Produção)

20 Ozualdo Candeias (Direção, roteiro, fotografia e montagem); Michel Saddi (Produção)

21 Ozualdo Candeias (Produção, direção, roteiro, fotografia e montagem); Governo do Estado de S. Paulo (Financiamento)

22 Ozualdo Candeias (Produção e direção); Eliseo Fernandes (Fotografia); Máximo Barro (Montagem); Governo do Estado de S. Paulo (Financiamento)

23 Ozualdo Candeias (Direção); Eliseo Fernandes (Fotografia);Luiz Elias (Montagem); Virgílio T. Nascimento (Produção) 
sobre as imagens da caixa que coleta o dinheiro dos fiéis. Em termos gerais, as ironias somam-se aos descompassos de significação entre imagens e locução, colaborando em especial para uma crítica ao aproveitamento da fé, que ganhará corpo e desdobramentos em futuros trabalhos do cineasta, como $O$ Candinho (1976), Aopção (1981) e As Belas da Billings (1987).

Ensino industrial é um documentário institucional feito para propagandear os esforços do governo Carvalho Pinto (1959-63) na implementação do ensino profissional das escolas técnicas. A estrutura do filme baseia-se na fala de uma senhora, sempre em off, que relata as experiências do neto em sua formação e escolha profissional. O neto é o personagem principal, cujo crescimento é acompanhado pelo filme. Dentro da categoria de documentários institucionais, porém, Ensino Industrial é um tipo engenhoso, documentário encenado que usa a voz de uma das personagens, para propagandear os feitos do governo em tom lúdico de anedota, cumprindo a função da usual voz over de um narrador externo. ${ }^{24}$

Mesmo dentro da proposta de um documentário encenado, identificamos algumas liminaridades, que surgem gradualmente, não apenas no gosto pela irreverência das crianças, mas também através do trabalho com o som e os bruscos movimentos de câmera: a primeira imagem é aquela de uma luminária a partir de um vertiginoso ricochetear de câmera, quase que simulando uma irreverência, própria às crianças em brincadeiras de periferia. Poderia ser a irreverência do próprio Candeias, cuja experimentação visual com movimentos óticos e de câmera extrapola o universo de oficialidade, próprio a um curta de propaganda institucional.

Assim, a passagem do rapazote à adolescência será representada pelo movimento do corpo, do menino que avança em direção à câmera e que se transforma em homem formado, distanciando-se da lente no final do movimento. A passagem do Ginásio para a Escola Técnica é mediada por nervosos chicotes de câmera, simulado o percurso do olhar pelas fachadas de tais instituições. Nos planos com os boletins de notas do neto, assim como alguns dos planos que fecham sequências maiores, percebemos mais ricocheteares. Cria-se assim um ritmo visual, em diálogo com a história contada, mas que a extrapola, reafirmando a irreverência anti-servil presente na imagem inicial do filme. Em Ensino Industrial, a liminaridade apresenta-se num subtexto particular, construído pela performance dos bruscos movimentos óticos e de câmera, que

24 Apesar da distância, seria interessante encontrar sintonias, por exemplo, com a proposta de Night Mail (1936), documentário com trechos encenados, de Cavalcanti, exibido por ele em 1949, durante o curso no Seminário de Cinema do MASP. 
sugerem uma rebeldia própria ao universo das crianças retratadas, mas também do futuro universo visual dos filmes de Candeias.

No filme Rodovias, documentário institucional realizado pelo cineasta no mesmo ano que Ensino Industrial, é tematizado o plano de ação do Governo Carvalho Pinto na construção de estradas de rodagem. Nele, a cidade de São Paulo aparece como o ponto de partida das estradas que desbravam o interior do Estado, permitindo a troca de produtos e o progresso. O modelo de documentário expositivo é predominante, com destaque à voz over, que expõe dados sobre o crescimento populacional e industrial urbano, bem como sobre a construção das estradas de rodagem do Estado de São Paulo. A grandiloquência da voz over mimetiza a magnitude do progresso, alcançado pelas obras do Governo do Estado de São Paulo. Depois de uma breve passagem pela São Paulo central, o filme se desdobra pelos campos do interior do Estado, apresentando paisagens interioranas, obras de estradas de rodagem, além de vias já pavimentadas e em funcionamento. Para fugir de uma possível monotonia, propiciada por uma sucessão de vias sem muitas ações além de carros em deslocamento, notamos uma solução muito própria ao estilo de Ozualdo Candeias: movimentos óticos e de câmera, usados na passagem entre diferentes sequências, criando uma espécie de moldura, carregada de tensão e bom humor. Placas de sinalização, em vias ou recantos descampados, ganham tensa animação, por meio de enquadramentos tortos, chicotes de câmera, ou de bruscas panorâmicas que se movimentam das placas para a via. Alguns dos planos abertos, ao apresentar o vai e vem de automóveis, rompem-se de improviso com zooms. Apesar de certa sutileza, tal moldura estilística causa interferências no predominante modelo expositivo, abrindo espaço para reverberações autorais, do estilo cinematográfico rude e agressivo que ganhará peso em obras posteriores.

Já nos filmes da série Marcha para o Oeste, os traços liminares encontram-se nos descompassos entre as pacatas vistas mato-grossenses e a grandiloquência metropolitana sugerida pela narração em voz over. Os institucionais Marcha para o Oeste n. $3(1955-58)^{25}$ e Marcha para o Oeste n. 5 (1958-59) foram produzidos por Michel Saddi, que captava dinheiro junto a lideranças políticas e comerciantes locais do Mato Grosso do Sul. Os dois filmes apresentam cidades do MS, respectivamente Campo Grande e Corumbá, visando a sua divulgação para outros Estados, possíveis investidores, além da

25 Tais filmes são datados pela Filmografia Brasileira entre 1960-65. Uma análise detida, porém, aponta para o período entre 1955-59. A Marcha para Oeste n. 3, por exemplo, mostra o prefeito de Campo Grande Marcílio de Oliveira Lima (prefeitura 1955-59), num período anterior à inauguração do Mercado Municipal da cidade, que é de 1958. Isso permite supor que a provável data de filmagem situase entre 1955-58 - exato período em que Candeias cursava o Seminário de Cinema do MASP. 
afirmação das realizações e progressos para a própria população de MS. O tom geral é grandiloquente, enaltecendo a ação dos prefeitos e das indústrias locais. O título "Marcha para o oeste", não parece apenas uma coincidência gratuita, reafirmando um conhecido imaginário, originalmente associado ao progresso e à interiorização, com a venda de terras, os avanços de colônias agrícolas e o mito de uma cruzada em direção ao Oeste, que fora propagandeado durante o Estado Novo (1937-45). O imaginário é aqui retomado e aplicado ao espaço urbano das pacatas Campo Grande e Corumbá.

Em Marcha para o Oeste n. 5, a tentativa de atribuir grandiloquência a Corumbá é permeada por uma ironia liminar. A voz over dispara dados históricos em tom altaneiro, colocando o município como um dos mais ricos do país. Anuncia-se também o monumento em homenagem ao general que teria libertado a cidade após a Guerra do Paraguai, postado entre "caprichosas alamedas e vegetação exuberante". Enquanto isso, notamos paisagens de uma cidade permeada por árvores, incluindo passagem por um ambiente descampado com um prédio ao fundo, bem como uma avenida repleta de coqueiros e apenas alguns carros.

No mesmo filme, ao propagandear um centro com comércio "sólido e movimentado", vemos apenas uma avenida interiorana, com algumas construções e transeuntes. A estranheza é reafirmada pela construção visual que, por meio de panorâmicas, tentativas de contreplongées, planos tomados de cima de alguns dos raros prédios, bem como por uma montagem somando planos relativamente curtos, atribui tacanha vertiginosidade a um espaço interiorano. Tal lógica ganha variações ao longo do filme institucional, inclusive quando algumas das limitadas indústrias locais, de ferro, farinha ou guaraná, são mostradas através de montagem rítmica e gradações de planos fechados.

Ao longo de Marcha para o Oeste n. 5, portanto, a liminaridade apresentase pela sutil ironia, bem como pela construção de um olhar descompassado que, na tentativa de atribuir cosmopolitismo à interiorana Corumbá, desdobrase num espaço ambíguo, entre o rural e o urbano. A mesma estranheza será encontrada nas sequências finais de Marcha para o Oeste $n$. 3, onde a voz over anuncia um considerável fluxo de comércio, nacional e internacional, sobre as imagens de humildes canoas de madeira, encostadas na lamacenta margem do Rio Paraguai.

Os ruídos ante ao modelo expositivo voltarão à tona em Casa André Luiz (1966). Neste documentário institucional, com produção deVirgílioT. Nascimento e direção de fotografia de Eliseo Fernandes, propagandeia-se o trabalho de um orfanato para deficientes intelectuais. Há um predomínio da voz over, que explica o funcionamento da instituição, enquanto as imagens apresentam as 
ações cotidianas encenadas pelos funcionários. As atividades rotineiras incluem os cuidados para a admissão das crianças, os exames rotineiros, as tarefas administrativas, a alimentação, a divisão interna das crianças por sexo, além de dados sobre a manutenção econômica do orfanato.

Algumas sequências realizadas no pátio, porém, a partir de uma interação poética entre câmera e crianças, sugerem rupturas em relação ao documentarismo clássico expositivo. Trata-se de brechas criativas, onde o trabalho de fotografia atem-se às fisionomias e deformidades, com sucintas ironias ante à seriedade da voz over. A partir de movimentos bruscos e enquadramentos tortos, a câmera embrenha-se pelos olhares, gestos corporais e andares mancos, mimetizando uma espécie de dislexia visual, numa tentativa de figurar a situação mental dos pequenos órfãos. A atenção às fisionomias e deformidades, associada à tentativa de contemplar a própria visão de mundo dos personagens, terá desdobramentos posteriores na obra de Candeias, especialmente com uma tendência ao uso do estilo indireto livre. Será o caso de A margem (1967), por exemplo, onde as trocas de olhares a partir de planosponto-de-vista (Branigan, 2005) sugerem a situação de personagens à deriva. Ou então, o filme O Candinho (1976), onde os movimentos circulares da fotografia aproximam-se da situação mental de um caipira.

\section{Considerações finais}

Os documentários aqui debatidos, no contexto dos anos 1950-60 e das relações estabelecidas por Candeias no Seminário de Cinema do MASP, sugerem que o estudo do estilo próprio aos seus filmes não podem limitar-se ao mapeamento de um conjunto fixo de traços narrativos. Pelo contrário, a riqueza está justamente nas relações liminares, estabelecidas pela obra do cineasta com determinados gêneros e linguagens, em grande parte pautadas por ironias e ambiguidades. Trata-se de um estilo calcado em ruídos, ante aos modelos de cinema com os quais se dialoga. Diante dos traços expositivos das atualidades e documentários institucionais, as frentes de liminaridade aqui debatidas sugerem breves ironias, que serão radicalizadas ao longo dos anos 1960-70. No contexto do cinema da Boca do Lixo, com variações, tal lógica será extrapolada para os diálogos com o western, o pornô, o cinema culto de Ruben Biáfora e Walter Hugo Khouri, as vanguardas francesas dos anos 1920, a nouvelle vague, o cinema de estrada, entre outras influências

O Seminário de Cinema do MASP, por sua vez, não se limita a um contexto de formação para Candeias. Tal experiência de educação colocaria alguma mão de obra no mercado cinematográfico paulista, uma geração formada junto às empresas dos anos 1950. Como Candeias, parte de tais profissionais seria 
reabsorvida pelo ciclo cinematográfico da Boca do Lixo, ao longo dos anos $1960-$ 70, transitando entre dois momentos industriais distintos do cinema paulista, primeiramente pautado pela absorção de modelos estrangeiros e, depois, pela incorporação irônica e debochada dos mesmos.

Tomando por alegoria o trajeto de Candeias e do cinema paulista, o crítico Avellar nos lembra que a tentativa de um cinema brasileiro culto, tal como empreendido pela Vera Cruz, teria gerado dentro de si o seu oposto. $\mathrm{Ou}$ seja, o cinema de Candeias, com sua "forma bruta deselegante, entre o ingênuo e o desarticulado, e com um quê de grotesco" (Avellar, 2002, p. 36), gestado às margens do cinema industrial dos anos 1950, e com ele estabelecendo uma relação de interdependência.

\section{REFERÊNCIAS}

ABREU, Nuno César. Boca do Lixo: cinema e classes populares. Campinas/SP: Unicamp, 2006.

AVELLAR, J. C. Três notas sobre o que está no centro de A margem. In: Ozualdo R. Candeias: 80 anos. São Paulo: CCBB, 2002, p. 19-31.

BARBOSA e SILVA, Florentino. Um Seminário. Habitat, São Paulo, n. 2, p. 82-83, jan.mar. 1951.

BARDI, Pietro Maria. O Museu de Arte de São Paulo. Habitat, São Paulo, n. 1, p. 17, out.dez. 1950.

1947-1977. In. MUSEU DE ARTE DE SÃO PAULO. MASP Assis Chateaubriand Ano 30. São Paulo: MASP, 1978. p. 8-9.

BERNARDET, Jean-Claude. In: Ozualdo R. Candeias. São Paulo: Centro Cultural Banco do Brasil, 2002.

O autor no cinema. São Paulo: Brasiliense/EDUSP, 1994.

BORDWELL, David. Sobre a História do estilo cinematográfico. Campinas/SP: Unicamp, 2013.

La narración en el cine de ficción. Barcelona: Paidós, 1996.

Figuras traçadas na luz. Campinas/SP: Papirus, 2008.

. THOMPSON, Kristin. Film Art: an introduction. Nova York: The MacGraw-Hill Companies, 1997.

BRANIGAN, Edward. O plano-ponto-de-vista. In: RAMOS, Fernão Pessoa (Org.). Teoria Contemporânea do Cinema, v. 2, São Paulo: Editora Senac São Paulo, p. 251275, 2005. 
CANDEIAS, O. Depoimento para 30 anos de cinema paulista. Cadernos da Cinemateca Brasileira, São Paulo, n. 4, p. 75-87, 1980.

CATANI, Afrânio Mendes. O romance do Gato preto: Carlos Ortiz e a história do cinema brasileiro. In: MACHADO JÚNIOR, Rubens; SOARES, Rosana de Lima; ARAÚJO, Luciana Corrêa de. (Org.). Estudos de Cinema - Socine VIII, São Paulo: Annablume; Socine, p. 295-303, 2007.

A sombra da outra: a cinematográfica Maristela e o cinema industrial paulista dos anos 50. São Paulo: Panorama, 2002.

DOUCHET, Jean. O corpo. In: OLIVERIA, Luis Miguel (Org.). Nouvelle Vague. Lisboa: Cinemateca portuguesa/ Museu do cinema, 1999.

GAMO, Alessandro Constantino. Aves sem rumo: a transitoriedade no cinema de $\mathrm{O}$. Candeias. 2000. Dissertação (Mestrado em Multimeios) - Instituto de Artes/ UNICAMP, Campinas, 2000.

GALVÃO, Maria Rita. Burguesia e cinema: o caso Vera Cruz. Rio de Janeiro: Civilização Brasileira, 1981.

GOMES, Paulo Emílio Salles. A expressão social dos filmes documentais no cinema mudo brasileiro (1898-1930). In: CALIL, C.; MACHADO, M. (Orgs.). Um intelectual na linha de frente, São Paulo: Brasiliense; Rio de Janeiro: Embrafilme, p. 323329, 1986.

GUIMARÃES, Clotilde Borges. A introdução do som direto no cimento documentário brasileiro na década de 1960.2008. Tese (Doutorado)-Escola de Comunicações e Artes, Universidade de São Paulo, 2008.

MACHADO JÚNIOR, Rubens. Uma São Paulo de revestrés. Significação, São Paulo, n. 28, p. 111-131, 2007.

MARGULIES, Marcos. Documentários. Habitat, São Paulo, n. 5, p. 33-36, 1951.

MUSEU... Diário da Noite, São Paulo, 30 ago. 1952.

NICHOLS, Bill. Introdução ao documentário. Campinas/SP: Papirus, 2012.

PANOFSKY, Erwing. Three essays on style. Cambridge: MIT Press, 1995.

PASOLINI, Pier Paolo. A poesia no novo cinema. Revista Civilização Brasileira, Rio de Janeiro, n. 7, p. 267-287, 1966.

RAMOS, Fernão. Cinema Marginal (1968/1973) - a representação em seu limite. São Paulo: Brasiliense, 1987.

Os novos rumos do cinema brasileiro (1955-1970). História do Cinema Brasileiro. São Paulo: Art Editora, 1987. 
RAMOS, José Mário Ortiz. Cinema, Estado e Lutas Culturais. Rio de Janeiro: Paz e Terra, 1983.

AUTRAN, Artur; HEFFNER, Hernani; GARDNIER, Ruy. Biografia. A margem da Boca. Ozualdo R. Candeias: 80 anos, São Paulo: CCBB, p. 19-31, 2002.

O pensamento industrial cinematográfico brasileiro. São Paulo: Hucitec, 2013.

SCHAPIRO, Meyer. Style, artiste et société. Paris: Gallimard, 1982.

SCHINCARIOL, Zuleica. Através do espaço do acervo: MASP na 7 de abril. Dissertação (Mestrado em Arquitetura) - Faculdade de Arquitetura e Urbanismo, Universidade de São Paulo, 2000.

SIMÕES, Inimá. O imaginário da Boca. Cadernos Idart 6. São Paulo: Secretaria Municipal de Cultura do Estado de S. Paulo, Centro de Documentação e Informação sobre Arte Brasileira Contemporânea, 1981.

STENHEIM, Alfredo. Máximo Barro: talento e altruísmo. São Paulo: Imprensa Oficial, 2009.

TURNER, Victor. O processo ritual: estrutura antiestrutura. Petrópolis: Vozes, 1974.

UCHOA, Fábio. Perambulação, silêncio e erotismo nos filmes de Ozualdo Candeias. (1967-83) Tese. (Doutorado em Ciências da Comunicação) - Escola de Comunicações e Artes, Universidade de São Paulo, 2013.

VAN GENNEP, Arnold. Os ritos de passagem. Petrópolis: Vozes, 1978.

WOLFFLIN, Henrich. Conceitos fundamentais da história da arte. São Paulo: Martins Fontes, 2000.

\section{Arquivos Consultados}

Arquivo Histórico do MASP - Centro de Documentação do Museu de Arte de São Paulo.

Arquivo Plínio Garcia Sanchez - Centro de Documentação e Pesquisa da Cinemateca Brasileira. 